\title{
Food at checkouts in non-food stores: a cross-sectional study of a large indoor shopping mall
}

\author{
James Wright ${ }^{1}$, Erin Kamp ${ }^{1}$, Martin White ${ }^{2,3} \uparrow$, Jean Adams ${ }^{2,3,} \uparrow$ and Sarah Sowden ${ }^{2,3, *}$ \\ ${ }^{1}$ Faculty of Medical Sciences, Newcastle University, Framlington Place, Newcastle upon Tyne, UK: ${ }^{2}$ Institute of Health \\ \& Society, Newcastle University, Baddiley-Clark Building, Newcastle upon Tyne NE2 4AX, UK: ${ }^{3}$ Fuse, UKCRC \\ Centre for Translational Research in Public Health, Newcastle University, Newcastle upon Tyne, UK
}

Submitted 1 July 2014: Final revision received 13 November 2014: Accepted 16 December 2014: First published online 25 February 2015

\begin{abstract}
Objective: To investigate the display of food at non-food store checkouts; and to classify foods by type and nutrient content, presence of price promotions and whether food was at child height.

Design: Cross-sectional survey of checkout displays at non-food stores. Foods were classified as 'less healthy' or healthier using the UK Food Standards Agency's Nutrient Profile Model. Written price promotions were recorded. Child height was defined as the sight line of an 11-year-old approximated from UK growth charts. Setting: A large indoor shopping mall, Gateshead, UK, February-March 2014.

Subjects: Two hundred and five out of 219 non-food stores in the shopping mall directory which were open for trading.

Results: Thirty-two (15.6\%) of 205 non-food stores displayed food at the checkout. All displayed less healthy foods, and fourteen (43.8\%) had healthier foods. Overall, 5911 checkout foods were identified. Of these, 4763 (80.6\%) were 'less healthy'. No fruits, vegetables, nuts or seeds were found. Of 4763 less healthy foods displayed, 195 ( $4 \cdot 1 \%$ ) were subject to price promotions, compared with twelve of 1148 (1.0\%) healthier foods $\left(\chi^{2}(\mathrm{df}=1)=25 \cdot 4, P<0 \cdot 0001\right)$. There was no difference in the proportion of less healthy $(95 \cdot 1 \%)$ and healthier $(96 \cdot 2 \%)$ foods displayed at child height.

Conclusions: Almost one-sixth of non-food stores displayed checkout food, the majority of which was 'less healthy' and displayed at child height. Less healthy food was more likely to be subject to a written price promotion than healthier food. Further research into the drivers and consequences of checkout food in non-food stores is needed. Public health regulation may be warranted.
\end{abstract}

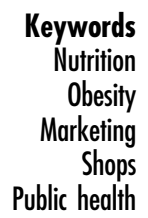

The increasing prevalence of overweight and obesity in the UK and globally is due to an imbalance between energy intake and expenditure ${ }^{(1-3)}$. Among numerous other factors, the exposure of individuals to energy-dense, nutrient-poor foods in everyday life has been recognized as a contributory factor in the development of obesity ${ }^{(1-3)}$. An obesogenic environment is defined as the sum of influences that the surroundings, opportunities, or conditions of life have on promoting obesity in individuals or populations $^{, 4,5)}$. One potential contributor to the obesogenic environment which has gained media ${ }^{(6,7)}$, campaign $\operatorname{group}^{(8,9)}$ and international research ${ }^{(10-16)}$ attention is the display of unhealthy foods at supermarket checkouts.

Previous research in UK convenience supermarkets found that food was often displayed at checkouts and

$†$ Current affiliation: Centre for Diet \& Activity Research, MRC Epidemiology Unit, University of Cambridge School of Clinical Medicine, Cambridge Biomedical Campus, Cambridge, UK. tended to be both unhealthy and in a position to attract children $^{(10)}$. Similar findings have been reported from Australia ${ }^{(13,15)}$, the $\mathrm{USA}^{(14)}$ and in an international comparison across eight countries ${ }^{(16)}$. Checkout food prompts impulsive purchases and purchasing requests from children $^{(15,17)}$, which consumers find hard to resist and recognize as a potential contributor to obesity ${ }^{(9)}$. Children are a large market for retailers ${ }^{(18)}$ and food marketing is known to affect children's food preferences, knowledge and behaviour ${ }^{(18)}$. The balance of healthy to less healthy foods displayed at checkouts influences customers' behaviour, with healthy foods being more likely to be selected when they are in the majority ${ }^{(19)}$. Price promotions are also known to influence purchasing ${ }^{(20,21)}$ and may further contribute to impulse purchases.

Anecdotal reports ${ }^{(22-24)}$ and a 2011 survey in London of six stores by the Children's Food Campaign ${ }^{(8)}$ suggest that the practice of displaying and promoting unhealthy food at checkouts extends beyond supermarkets to non-food stores. 
Research in pharmacies in the USA confirms that more than half of them display food (including sugar-sweetened beverages) for sale within $3 \mathrm{~m}$ (10 ft) of checkouts ${ }^{(25)}$. A convenience sample of 1082 non-food stores in the USA found that $41 \%$ stocked food and that $44 \%$ of this was within arm's reach of the checkout queue ${ }^{(26)}$. As far as we are aware, to date no published research has particularly focused on checkout food across all types of non-food stores and none has been conducted outside the USA. Therefore the aims of the present research were to: (i) investigate the display of foods at non-food store checkouts; and (ii) classify foods by type and nutrient content, presence of price promotions and whether food was displayed at child height.

\section{Method}

A cross-sectional survey of non-food stores was conducted in an indoor shopping mall in Gateshead, UK, FebruaryMarch 2014. The out-of-town indoor shopping mall is the largest in Europe ${ }^{(27)}$ and a regional centre with good car, bus and train links. It attracts 23 million visitors per year ${ }^{(27)}$ (approximately 63000 daily) and is equivalent in scale to a UK city centre shopping area. Seventy-three per cent of shoppers are female, $53 \%$ are aged 16-44 years and $57 \%$ are middle class $\left(\mathrm{ABC} 1^{(28)}\right)^{(27)}$. Hence, the survey encompassed a large number of stores with different price points and merchandise, serving a wide demographic in a relatively compact area, including all the main UK high-street stores.

The centre store directory provided for visitors was used as the sampling frame and to identify stores which met the inclusion criteria. Supermarkets and other stores that primarily sold food items, either hot (e.g. fast food) or cold (e.g. confectionery stores), and food departments within department stores, were excluded. Stores in the surrounding retail park were also excluded, as were the apparently temporary retail carts found in the centre's walkways. The store directory was also used to define and assign store category (book/card/stationery, customer services, department stores, jewellery, music/technology, opticians, shoes, specialist, sports/outdoors, toys/games/ gadgets, travel agents, fashion and hair/beauty), which enabled analysis of whether checkout displays varied according to the type of non-food store.

Checkouts were defined as any compulsory areas that shoppers had to pass through to pay for their goods ${ }^{(10)}$. This included checkouts at store exits as well as anywhere else in stores. Many stores have one shared queuing aisle that is used for a number of payment points. In these cases, the total number of checkouts was recorded as the number of payment points present with each checkout beginning in the shared main queuing area. Food within arm's reach of any point of the checkout was defined as checkout food. We included both foods for sale and complimentary foods provided free to customers. Food was recorded in terms of the total number of food lines available (irrespective of package size), rather than the total volume of food or number of packets of food displayed.

Two researchers (E.K. and J.W.) visited each store and checkout food was identified and recorded using a prepiloted bespoke survey tool. Digital photographs were taken to assist with classification. Based on pilot data, the type (sweets, chocolate, high-calorie drinks, salty food, snack bars, biscuits, cake, chewing gum, low-calorie drinks/water, bruschetta/crackers) of all food lines available at each checkout was recorded. The nutritional content of all checkout food was obtained from product packages or manufacturers' websites and used to determine whether it was 'less healthy' or not using the UK Food Standard Agency's Nutrient Profile Model ${ }^{(29)}$. Those food lines that were classified as not 'less healthy' are referred to throughout as 'healthier' (the Nutrient Profile Model is not explicitly designed to identify foods which are healthy ${ }^{(29)}$ ).

It was also recorded which food lines were subject to written price promotions displayed on the food package or checkout display area. Child height was defined as the sight line of an 11-year-old approximated from UK growth charts $^{(30)}$. The height used was $146 \mathrm{~cm}$, which is $10 \mathrm{~cm}$ below (to approximate eye level) $156 \mathrm{~cm}$, which in turn is 2 SD above the mean height of an 11-year-old female (girls are taller than boys at this age) ${ }^{(30)}$.

To explore inter-rater reliability of the data collection methods, a random sample of $10 \%$ of stores, stratified by store type, was revisited by a second pair of researchers. There was more than $90 \%$ concordance for all variables collected.

The proportion of stores displaying food at checkouts was calculated as a percentage of all stores as well as by store category. To reflect customer experience, checkout food exposure was determined, which was defined as the total number of different food lines displayed on the journey from the start of the queuing area to the payment point. Any food lines displayed in a shared queuing aisle were multiple counted to reflect the total number of checkouts and hence possible different journeys from the start of the queue to each payment point. The percentage of checkout food exposures by food type that were less healthy or healthier was calculated for all stores and by store category. The mean number of food lines displayed per checkout for each store was calculated, and the mean number of food lines per checkout by store category (average checkout food exposure) derived from these. Previous research has found chewing gum to be the most common healthier alternative at checkouts. Chewing gum has limited nutritional value ${ }^{(10)}$, although it may have benefits in short-term appetite regulation ${ }^{(31)}$ and for dental health $^{(32)}$. With this in mind, sensitivity analysis was undertaken and the mean healthier checkout food 
exposures recalculated after exclusion of chewing gum. The ratio of less healthy to healthier mean checkout food exposures was calculated overall and for each story category. The proportion of less healthy and healthier checkout food exposures on promotion, and at child height, was calculated. The $\chi^{2}$ test was used to assess differences in proportions.

\section{Ethical considerations}

Ethical approval was not required as the study did not involve human subjects.

\section{Results}

A total of 313 stores were in the sampling frame, of which $219(70 \%)$ met the inclusion criteria. Fourteen stores listed in the directory were not present in the mall. The total number of stores open for trading and visited was 205 (94\% of those meeting the inclusion criteria).

Table 1 shows the proportion of stores with checkout food and the types of foods found by store category. Thirty-two (15.6\%) stores displayed checkout food; $83.3 \%$ of book/card/stationery stores, $71.4 \%$ of department stores, $33.3 \%$ of sport/outdoors stores and nearly a third (30.0\%) of toy/games/gadget stores had food at checkouts (Table 1). Stores in the customer services, jewellery, opticians, shoes and travel agent categories had no checkout food. All stores with checkout food had less healthy foods on display. Fourteen (43.8\%) of thirty-two had healthier food at checkouts. In total 5911 checkout food exposures were identified across 353 checkouts. Of these, 4763 ( $80.6 \%$ ) were less healthy foods, the majority of these being lines of sweets 2123 (44.6\%) and chocolate 2119 (44.5\%). Of the healthier exposures, 686 (59.8\%) were chewing gum and $403(35.1 \%)$ were water/lowcalorie drinks (Table 1).

Averaged across all stores displaying food, the mean number of food lines displayed per checkout was $15 \cdot 0$ (SD 19.7), with a mean of 11.9 (SD 14.8) being less healthy lines (Table 2). The average varied across store category (Table 2). There was also substantial variation between stores within each store category in terms of the average checkout food exposures, reflected in the frequently large standard deviations (Table 2).

Averaged across all stores displaying food, fashion had 21.5 less healthy checkout food exposures for every one healthier food exposure. The one store in the music/ technology category only displayed less healthy foods. With sensitivity analysis to exclude chewing gum from the healthier food lines, specialist and fashion stores also displayed only less healthy foods and books/cards/stationery and hair/beauty had the highest ratio of less healthy to healthier foods exposures, 68:1 and 30:1 respectively.

Of the eight categories of stores displaying less healthy checkout foods, five had less healthy lines subject to price promotions (Table 3). Overall, of 4763 less healthy food exposures, $195(4.1 \%)$ were subject to written price promotions. Only two categories of stores (books/cards/ stationery and sports/outdoors) had healthier food lines subject to price promotions. Of a total of 1148 healthier food exposures, twelve (1.0\%) were subject to price promotions (Table 3). The difference in promotional activity for less healthy and healthier food types was statistically significant $\left(\chi^{2}(\mathrm{df}=1, n 5911)=25 \cdot 4, P<0 \cdot 0001\right)$.

The majority $(95.3 \%)$ of checkout food was displayed below child height. However, there was no statistically significant difference between the proportion of less healthy (4528/4763, 95.1\%) and healthier (1104/1148, $96.2 \%)$ checkout foods displayed below child height $\left(\chi^{2}(\mathrm{df}=1, n 5911)=2 \cdot 5, P=0 \cdot 11\right)$.

\section{Discussion}

The present study is the first one we are aware of to particularly investigate the display of food at checkouts across the full range of non-food stores and the first study of food in non-food stores outside the USA ${ }^{(25,26)}$. In addition, and unlike previous research ${ }^{(25,26)}$, we classified foods by type and nutrient content, presence of price promotions and whether food is at child height. A notable proportion (16\%) of non-food stores had food on display at their checkouts and all of these displays included less healthy foods. More than $80 \%$ of checkout food displayed was defined as less healthy and was mostly confectionery. Healthier checkout food was almost exclusively either low-calorie drinks/water or chewing gum. No fruit, vegetables, nuts or seeds was found at any checkouts. Among stores with checkout food, the average customer would be exposed to twelve less healthy food lines and three healthier food lines during his/her journey through the checkout.

The presence of checkout food varied between store category, being absent in jewellery, customer services, opticians, shoe stores and travel agents, and most common in book/card/stationery and department stores. There was also variation between stores within each store category in the average number of lines of food displayed per checkout. The great majority of checkout food was displayed at child height, with no difference between less healthy and healthier foods in this respect. Written food promotions were uncommon and we did not pursue an analysis by store type for this reason, but less healthy foods were more frequently on promotion than healthier foods. The sampling frame chosen enabled the analysis of a large number of stores with different price points and merchandise, including all the main UK high-street stores. Visitors to the shopping mall span a cross-section of the population, by age, sex and social class ${ }^{(27)}$. Therefore, our findings are likely to be generalizable to other shopping malls and indeed the UK high-street shopping experience in general. However, a different range of non-food stores 


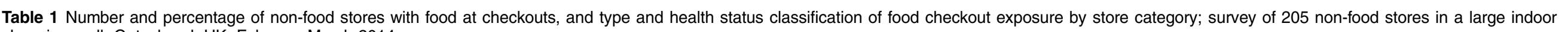
shopping mall, Gateshead, UK, February-March 2014

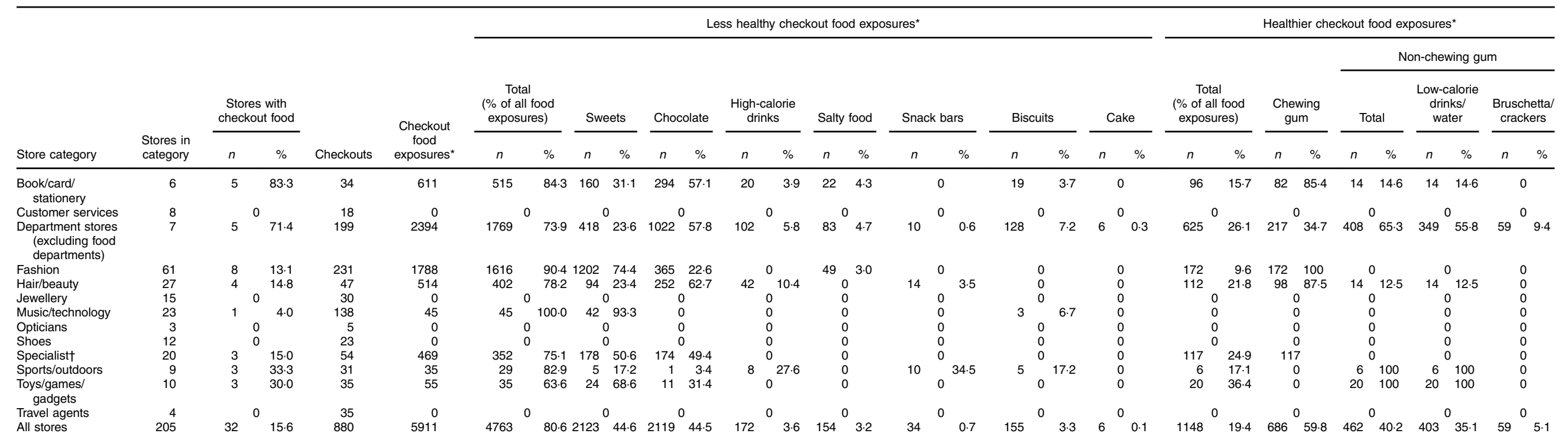

${ }^{*}$ Checkout food exposures $=$ number of food lines available for each checkout (i.e. food lines displayed in a shared queuing aisle will be identified against more than one checkout and hence included multiple times)

†'Specialist' was a miscellaneous store category which included, for example, 'Pound' stores (deep discount, general stores with a maximum item price of £1 (€1.21, $\$$ US 1.67)), art/print stores and wedding stores. 
Table 2 Mean checkout food exposures per store by store category and food health status classification; survey of 205 non-food stores in a large indoor shopping mall, Gateshead, UK, February-March 2014

\begin{tabular}{|c|c|c|c|c|c|c|c|c|c|c|c|c|}
\hline \multirow[b]{2}{*}{ Type of store } & \multicolumn{2}{|c|}{$\begin{array}{l}\text { Stores } \\
\text { with food }\end{array}$} & \multicolumn{2}{|c|}{$\begin{array}{l}\text { Checkout food } \\
\text { exposures* }\end{array}$} & \multicolumn{2}{|c|}{$\begin{array}{l}\text { Less healthy } \\
\text { checkout food } \\
\text { exposures }\end{array}$} & \multicolumn{2}{|c|}{$\begin{array}{l}\text { Healthier } \\
\text { checkout food } \\
\text { exposures }\end{array}$} & \multicolumn{2}{|c|}{$\begin{array}{l}\text { Healthier } \\
\text { checkout food } \\
\text { exposures } \\
\text { (excl. gum) }\end{array}$} & \multirow{2}{*}{$\begin{array}{l}\text { Ratio of mean less healthy to healthier } \\
\text { checkout food exposures }\end{array}$} & \multirow{2}{*}{$\begin{array}{l}\text { Ratio of mean less healthy to healthier } \\
\text { checkout food exposures (excl. gum) }\end{array}$} \\
\hline & $n$ & $\%$ & Mean & SD & Mean & SD & Mean & SD & Mean & SD & & \\
\hline Book/card/stationery & 5 & $83 \cdot 3$ & $26 \cdot 0$ & $19 \cdot 7$ & $20 \cdot 4$ & 14.4 & $5 \cdot 6$ & 9.4 & 0.3 & $0 \cdot 6$ & $3 \cdot 6: 1$ & $68 \cdot 0: 1$ \\
\hline Customer services & 0 & 0 & 0 & 0 & 0 & 0 & 0 & 0 & 0 & 0 & $\mathrm{n} / \mathrm{a}$ & $\mathrm{n} / \mathrm{a}$ \\
\hline $\begin{array}{l}\text { Department store (excluding } \\
\text { food departments) }\end{array}$ & 5 & 71.4 & $23 \cdot 7$ & $28 \cdot 6$ & $17 \cdot 5$ & $20 \cdot 2$ & $6 \cdot 2$ & 8.9 & 4.4 & $8 \cdot 7$ & $2 \cdot 8: 1$ & $4 \cdot 0: 1$ \\
\hline Fashion & 8 & $13 \cdot 0$ & $9 \cdot 1$ & 8.5 & 8.6 & 7.4 & 0.4 & $1 \cdot 3$ & 0 & 0 & $21.5: 1$ & $\mathrm{n} / \mathrm{a}$ - only less healthy food available \\
\hline Hair/beauty & 4 & 14.8 & $19 \cdot 0$ & $36 \cdot 0$ & $15 \cdot 0$ & $28 \cdot 0$ & 4.0 & $8 \cdot 0$ & 0.5 & 1 & $3 \cdot 75: 1$ & $30 \cdot 0: 1$ \\
\hline Jewellery & 0 & 0 & 0 & 0 & 0 & 0 & 0 & 0 & 0 & 0 & $\mathrm{n} / \mathrm{a}$ & $\mathrm{n} / \mathrm{a}$ \\
\hline Music/technology & 1 & 4.0 & 5.6 & 0 & $5 \cdot 6$ & 0 & 0 & 0 & 0 & 0 & $\mathrm{n} / \mathrm{a}$ - only less healthy food available & $\mathrm{n} / \mathrm{a}$ - only less healthy food available \\
\hline Opticians & 0 & 0 & 0 & 0 & 0 & 0 & 0 & 0 & 0 & 0 & $n / a$ & $\mathrm{n} / \mathrm{a}$ \\
\hline Shoes & 0 & 0 & 0 & 0 & 0 & 0 & 0 & 0 & 0 & 0 & $\mathrm{n} / \mathrm{a}$ & $\mathrm{n} / \mathrm{a}$ \\
\hline Specialist & 3 & $15 \cdot 0$ & $15 \cdot 2$ & $18 \cdot 4$ & $11 \cdot 2$ & $15 \cdot 5$ & 4.0 & 3.6 & 0 & 0 & $2 \cdot 8: 1$ & $\mathrm{n} / \mathrm{a}$ - only less health food available \\
\hline Sports/outdoors & 3 & $33 \cdot 3$ & 5.7 & $5 \cdot 0$ & $5 \cdot 0$ & $5 \cdot 3$ & 0.7 & $1 \cdot 1$ & 0.7 & $1 \cdot 1$ & $7 \cdot 1: 1$ & $7 \cdot 1: 1$ \\
\hline Toys/games/gadgets & 3 & $30 \cdot 0$ & 4.8 & $5 \cdot 5$ & $3 \cdot 1$ & $2 \cdot 7$ & 1.7 & $2 \cdot 9$ & 1.7 & $2 \cdot 9$ & $1 \cdot 8: 1$ & $1 \cdot 8: 1$ \\
\hline Travel agents & 0 & 0 & 0 & 0 & 0 & 0 & 0 & 0 & 0 & 0 & $\mathrm{n} / \mathrm{a}$ & $\mathrm{n} / \mathrm{a}$ \\
\hline All stores & 32 & $15 \cdot 6$ & $15 \cdot 0$ & $19 \cdot 7$ & 11.9 & $14 \cdot 8$ & 3.0 & 5.9 & 1.0 & $3 \cdot 6$ & $4 \cdot 0: 1$ & $11 \cdot 9: 1$ \\
\hline
\end{tabular}

$\mathrm{n} / \mathrm{a}$, not applicable, no checkout food within this category.

${ }^{*}$ The average number of food lines displayed per checkout for each store with checkout food was calculated, and the average food lines per checkout (mean checkout food exposure) by store category derived from these. 
Table 3 Number and percentage of checkout exposures to foods subject to written promotion, and at child height, by store category and food health status classification; survey of 205 non-food stores in a large indoor shopping mall, Gateshead, UK, February-March 2014

\begin{tabular}{|c|c|c|c|c|c|c|c|c|c|c|}
\hline \multirow[b]{3}{*}{ Type of store } & \multicolumn{5}{|c|}{ Less healthy checkout food exposures* } & \multicolumn{5}{|c|}{ Healthier checkout food exposures } \\
\hline & \multirow[b]{2}{*}{$n$} & \multicolumn{2}{|c|}{ On promotion } & \multicolumn{2}{|c|}{ At child height } & \multirow[b]{2}{*}{$n$} & \multicolumn{2}{|c|}{ On promotion } & \multicolumn{2}{|c|}{ At child height } \\
\hline & & $n$ & $\%$ & $n$ & $\%$ & & $n$ & $\%$ & $n$ & $\%$ \\
\hline Book/card/stationery & 515 & 112 & 21.7 & 508 & $98 \cdot 6$ & 96 & 8 & $8 \cdot 3$ & 61 & 63.5 \\
\hline Customer services & 0 & \multicolumn{2}{|r|}{ - } & \multicolumn{2}{|c|}{-} & 0 & \multicolumn{2}{|r|}{ - } & \multicolumn{2}{|c|}{ - } \\
\hline Department store (excluding food departments) & 1769 & 27 & 1.5 & 1649 & $93 \cdot 2$ & 625 & \multicolumn{2}{|r|}{0} & \multicolumn{2}{|c|}{$616 \quad 98.6$} \\
\hline Fashion & 1616 & \multicolumn{2}{|c|}{0} & 1548 & 95.8 & 172 & \multicolumn{2}{|r|}{0} & \multirow{2}{*}{\multicolumn{2}{|c|}{$\begin{array}{ll}172 & 100 \\
112 & 100\end{array}$}} \\
\hline Hair/beauty & 402 & 45 & $11 \cdot 2$ & 402 & 100 & 112 & \multicolumn{2}{|r|}{0} & & \\
\hline Jewellery & 0 & \multirow{2}{*}{\multicolumn{2}{|c|}{$\overline{0}$}} & & & 0 & \multirow{2}{*}{\multicolumn{2}{|c|}{-}} & \multicolumn{2}{|c|}{-} \\
\hline Music/technology & 45 & & & 38 & 84.4 & 0 & & & \multicolumn{2}{|c|}{-} \\
\hline Opticians & 0 & \multicolumn{2}{|c|}{$\begin{array}{l}0 \\
-\end{array}$} & & & 0 & \multicolumn{2}{|r|}{ - } & & \\
\hline Shoes & 0 & \multicolumn{2}{|c|}{ - } & & & 0 & \multicolumn{2}{|r|}{-} & \multicolumn{2}{|c|}{-} \\
\hline Specialist & 352 & \multicolumn{2}{|c|}{0} & 319 & $90 \cdot 6$ & 117 & \multicolumn{2}{|r|}{0} & 117 & 100 \\
\hline Sports/outdoors & 29 & 7 & $24 \cdot 1$ & 29 & 100 & 6 & 4 & $66 \cdot 7$ & 6 & 100 \\
\hline Toys/games/gadgets & 35 & 4 & 11.4 & 35 & 100 & 20 & \multirow{2}{*}{\multicolumn{2}{|c|}{$\begin{array}{l}0 \\
-\end{array}$}} & 20 & 100 \\
\hline Travel agents & 0 & \multicolumn{2}{|r|}{-} & \multicolumn{2}{|c|}{-} & 0 & & & \multicolumn{2}{|c|}{$20-$} \\
\hline All stores & 4763 & 195 & $4 \cdot 1$ & 4528 & $95 \cdot 1$ & 1148 & 12 & 1.0 & 1104 & 96.2 \\
\hline
\end{tabular}

${ }^{*}$ Checkout food exposure $=$ number of food lines available for each checkout (i.e. food lines displayed in a shared queuing aisle will be identified against more than one checkout and hence included multiple times).

and checkout displays may have been encountered in suburban high streets or rural stores.

The observational survey method had high inter-rater reliability, indicating that the recording of food products was accurately and objectively undertaken. Furthermore, using the Nutrient Profile model ensured objectivity in classifying foods as less healthy or not ${ }^{(29,33)}$. Although the Nutrient Profile model was originally designed for determining which food advertisements could be shown on children's television ${ }^{(29)}$, it has been used in research on supermarket checkout food ${ }^{(10)}$ and enables comparisons across contexts.

Data were collected during February and March, and in line with previous research carried out in the same season $^{(10)}$, a large amount of the less healthy foods found was related to Easter and Mothers' Day. It is possible that there are seasonal variations in checkout food, although it is likely that different seasonal foods are on display throughout the year. This could be confirmed by repeating the study at different points through the year.

The study did not assess the amount of food available at checkouts, only the variety of food lines available to customers. This is because it was not possible to quickly or accurately calculate display size or product volume (e.g. number of bags of confectionery) without handling products. This would have been more intrusive and disruptive and hence potentially less acceptable to shoppers and retail workers.

The eye line of $95 \%$ of 11-year-old girls was taken as the arbitrary cut-off to define child height for several reasons. First, products are most likely to be purchased when they are displayed at eye level ${ }^{(34)}$. Second, previous research has highlighted that lower heights fail to capture checkout food exposure for children riding in shopping carts $^{(10)}$. Third, pester power from children occurs at checkouts $^{(17)}$ and is a problem for parents ${ }^{(8,9)}$. The use of pester power extends beyond pre-schoolers to older children who are more actively involved in purchase decisions ${ }^{(35,36)}$. Children in the UK leave primary school at 11 years and as such this is an arbitrary marker for when children may be less likely to accompany parents to stores and exert pester power. As nearly all the food documented was present below the height chosen, it may be informative to explore foods displayed at several different heights.

The majority of price promotions identified were ' 2 for 1 ' or price reductions. Although not classed as price promotions here, many other less healthy products were advertised as 'great value' or available in a 'bigger pack' which could be misconstrued by customers as indicating the product is on offer $^{(37)}$. Three stores in the hair/beauty category displayed free checkout food in the form of jars of sweets at child height for customers to take once they had paid.

The present study investigated only written price promotions displayed on or near products. Verbal prompts promoting foods from the store staff at the checkout were not included. Assessing verbal promotion would require test purchases in all stores or observation of customer checkout interactions. Neither was feasible in the current study. Furthermore, the research only explored the presence or absence of checkout food, not how this influences food purchasing or eating behaviours. It is reasonable to assume that stores would only stock products at their checkouts that are purchased.

The current research suggests the display of food at non-food stores is less widespread than in supermarkets ${ }^{(10,13,14,16)}$. Nevertheless, a notable proportion of non-food stores did display checkout food. Unlike supermarkets, checkout food in non-food stores may target people who do not intend to purchase food and at times of the day when they are not considering eating. 
In line with supermarkets ${ }^{(10,13,14,16)}$, non-food stores stocked primarily less healthy checkout foods and during an average checkout journey customers would be exposed to four times as many less healthy foods as healthier ones. This is important because when a higher proportion of checkout foods displayed are less healthy, people tend to choose less healthy foods ${ }^{(19)}$.

The almost ubiquitous display of food at child height is consistent with research in supermarket contexts ${ }^{(10)}$ and important given concerns over food marking to children and childhood obesity $^{(18)}$. Ninety-five per cent of food displayed at child height at non-food store checkouts in the present study is banned from being advertised during children's television in the $\mathrm{UK}^{(29)}$. Further consideration of where and when it is and is not appropriate to market less healthy foods to children may be valuable. Price promotion leads to a significant increase in sales ${ }^{(20,21)}$. The higher proportion of less healthy foods on promotion may steer customers to choose these over any healthier options available.

Investigation of the display of food at non-food stores in other sociodemographic and retail contexts, and research focusing on mechanisms aside from written price promotions for promoting the sale of food at checkouts, would further our understanding of the relationship between checkout food and consumer behaviour. Mixed-methods research is needed to examine the drivers and consequences of food displayed at checkouts of non-food stores.

Substantial literature has documented the display of unhealthy foods at the checkout in supermarkets ${ }^{(10,13,14,16)}$, leading to advocacy for public health action ${ }^{(8,9,12)}$. Such action may have to extend to non-food stores. The variation in the display of checkout food between and within store categories found suggests action targeted at specific stores or chains of stores, rather than universal action across the non-food retail sector or by retail category, is appropriate.

Several supermarkets in the UK and elsewhere have recently pledged to remove unhealthy foods from checkouts $^{(16,38,39)}$. However, this self-regulatory approach is haphazard and not all retailers have committed to more responsible stocking of checkouts ${ }^{(6)}$. Regulation, such as that limiting television marketing of food products to children in the $\mathrm{UK}^{(40)}$, may be warranted. However, regulation is viewed by some as unfairly constraining consumer choice ${ }^{(35)}$. Encouraging retailers to increase the provision of healthier, relative to less healthy, checkout food may also be worth considering ${ }^{(16,19)}$, as could working with the non-food retail industry to find substitute checkout products that protect profit margins without potentially adversely impacting on customers' health.

\section{Acknowledgements}

Acknowledgements: The authors thank Matthew Holmes and Elizabeth Parrott, Newcastle University, for collecting the data required to determine inter-rater reliability.
Financial support: This research received no specific grant from any funding agency in the public, commercial or not-for-profit sectors. S.S. is funded by the NHS through Health Education North East. J.W. and E.K. are medical students at Newcastle University and carried out the research as part of their degree programme. At the time the research was conducted, M.W. was director and J.A. a member of academic staff in Fuse, the Centre for Translation Research in Public Health (www.fuse.ac.uk). Fuse is a UK Clinical Research Collaboration (UKCRC) Public Health Research Centre of Excellence. Funding for Fuse from the British Heart Foundation, Cancer Research UK, Economic and Social Research Council, Medical Research Council and the National Institute for Health Research, under the auspices of the UK Clinical Research Collaboration, is gratefully acknowledged. Views expressed in this paper do not represent those of the funders or UKCRC. The funders had no role in study design, data collection and analysis, decision to publish, or preparation of the manuscript. Conflict of interest: None. Authorship: S.S. conceived the idea for the research. All authors contributed to study design and development of study methods. E.K. and J.W. collected and analysed the data and drafted the manuscript with S.S. All authors interpreted the findings, critically reviewed drafts of the manuscript and approved the final version. S.S. is guarantor. Ethics of buman subject participation: Ethical approval was not required as the study did not involve human subjects.

\section{References}

1. World Health Organization (2014) Obesity and Overweight. WHO Fact Sheet no. 311. Geneva: WHO; available at http:// www.who.int/mediacentre/factsheets/fs311/en/

2. Jebb SA, Kopelman P \& Butland B (2007) Executive summary: FORESIGHT 'Tackling Obesities: future choices' project. Obes Rev $\mathbf{8}$, vi-ix.

3. Public Health England (2014) Causes of obesity. http:// www.noo.org.uk/NOO_about_obesity/causes (accessed February 2015).

4. Swinburn B \& Egger G (2002) Preventive strategies against weight gain and obesity. Obes Rev 4, 289-301.

5. Swinburn B, Egger G \& Raza F (1999) Dissecting obesogenic environments: the development and application of a framework for identifying and prioritizing environmental interventions for obesity. Prev Med 29, 563-570.

6. Poulter S (2014) Sweets at the checkout will stay as stores rebel over ban: Supermarkets resist call from health campaigners to remove temtation from the tills. Daily Mail 19 April. http://www.dailymail.co.uk/news/article-2608182/ Sweets-checkout-stay-stores-rebel-ban-Supermarkets-resistcall-health-campaigners.html (accessed April 2014).

7. Delmar-Morgan A (2013) Sweets at supermarket tills are 'fuelling obesity crisis'. The Independent 16 September. http://www.independent.co.uk/life-style/health-and-families/ health-news/sweets-at-supermarket-tills-are-fuelling-obesitycrisis-8818094.html (accessed September 2013).

8. Children's Food Campaign (2012) Checkouts checked out: how supermarkets and high street stores promote junk food to children and their parents. http://www.sustainweb.org/ publications/?id=212 (accessed February 2015). 
9. Safefood (2014) Safefood asks supermarkets to introduce healtheir checkouts. http://www.safefood.eu/News/2014/ safefood-asks-supermarkets-to-introduce-healthier.aspx (accessed February 2014).

10. Horsley JA, Absalom KAR, Akiens EM et al. (2014) The proportion of unhealthy foodstuffs children are exposed to at the checkout of convenience supermarkets. Public Health Nutr 17, 2453-2458.

11. Anon. (2012) Chocolate at the checkout is a risk to public health. BMJ 345, e6921.

12. Cohen DA \& Babey SH (2012) Candy at the cash register - a risk factor for obesity and chronic disease. $N$ Engl J Med 367, 1381-1383.

13. Thornton L, Cameron A, McNaughton S et al. (2012) The availability of snack food displays that may trigger impulse purchases in Melbourne supermarkets. BMC Public Health 12, 194.

14. Miller C, Bodor JN \& Rose D (2012) Measuring the food environment: a systematic technique for characterizing food stores using display counts. J Environ Public Health $\mathbf{2 0 1 2}$ 707860.

15. Dixon H, Scully M \& Parkinson K (2006) Pester power: snackfoods displayed at supermarket checkouts in Melbourne, Australia. Health Promot J Aust 17, 124-127.

16. Thornton L, Cameron A, McNaughton S et al. (2013) Does the availability of snack foods in supermarkets vary internationally? Int J Behav Nutr Phys Act 10, 56.

17. Campbell S, James EL, Stacey FG et al. (2014) A mixedmethod examination of food marketing directed towards children in Australian supermarkets. Health Promot Int 29, 267-277.

18. Harris JL, Pomeranz JL, Lobstein T et al. (2009) A crisis in the marketplace: how food marketing contributes to childhood obesity and what can be done. Annu Rev Public Health 30 , 211-225.

19. van Kleef E, Otten K \& van Trijp HC (2012) Healthy snacks at the checkout counter: a lab and field study on the impact of shelf arrangement and assortment structure on consumer choices. BMC Public Health 12, 1072.

20. Gilbert DC \& Jackaria N (2002) The efficacy of sales promotions in UK supermarkets: a consumer view. Int J Retail Distrib Manage 30, 315-322.

21. Hawkes C (2009) Sales promotions and food consumption. Nutr Rev 67, 333-342.

22. Anderson AS \& Steele B (2014) Editoral. The Scottish Cancer Prevention Network Newsletter 5, issue 2; available at http:// www.cancerpreventionscotland.co.uk/wp-content/uploads/ newsletter/SCPN_Vol-5_Issue-2.pdf

23. Chorley M (2013) Junk food at checkouts under fire as health minister says she want to stop parents being perstered by children. Daily Mail, 30 October. http://www.dailymail.co. uk/news/article-2479785/Junk-food-WILL-banned-checkouts. html (accessed October 2013).

24. Children's Food Campaign (2011) Chips with your crayons? WH Smiths offers kids junk food meal vouchers. http://www. sustainweb.org/news/sep11_whsmits_junk_food_vouchers/ (accessed September 2011).
25. Whitehouse A, Simon A, French SA et al. (2012) Availability of snacks, candy and beverages in hospital, community clinic and commercial pharmacies. Public Health Nutr 15, 1117-1123.

26. Farley TA, Baker ET, Futrell L et al. (2010) The ubiquity of energy-dense snack foods: a National Multicity Study. Am J Public Health 100, 306-311.

27. intu Properties plc (2014) Intu Metrocentre, Gateshead, Key facts. http://www.intugroup.co.uk/where-we-do-it/our-centres/ intu-metrocentre/the-centre/\#/where-we-do-it/our-centres/ intu-metrocentre/key-facts/?\&_suid=14006633573100140068 8885181844 (accessed February 2015).

28. National Readership Survey (2014) National Readership Survey Social Grade Classification. http://www.nrs.co.uk/nrsprint/lifestyle-and-classification-data/social-grade/ (accessed June 2014).

29. Department of Health (2011) Nutrient Profiling Technical Guidance. London: Department of Health; available at https://www.gov.uk/government/uploads/system/uploads/ attachment_data/file/216094/dh_123492.pdf

30. Royal College of Paediatrics and Child Health, Department of Health \& Healthier Scotland (2012) Girls UK Growth chart 2-18 years. http://www.rcpch.ac.uk/system/files/protected/ page/NEW\%20Girls\%202-18yrs(4TH\%20JAN\%202012).pdf (accessed February 2015).

31. Hetherington MM \& Regan MF (2011) Effects of chewing gum on short-term appetite regulation in moderately restrained eaters. Appetite 57, 475-482.

32. Ly KA, Milgrom P \& Rothen M (2008) The potential of dental-protective chewing gum in oral health interventions. J Am Dent Assoc 139, 553-563.

33. Quinio C, Biltoft-Jensen A, De Henauw S et al. (2007) Comparison of different nutrient profiling schemes to a new reference method using dietary surveys. Eur J Nutr 46, 37-46.

34. Curhan RC (1973) Shelf space allocation and profit maximization in mass retailing. J Mark 37, 54-60.

35. Marshall D, O'Donohoe S \& Kline S (2007) Families, food, and pester power: beyond the blame game? J Consum Behav 6, 164-181.

36. Buijzen M \& Valkenburg PM (2008) Observing purchaserelated parent-child communication in retail environments: a developmental and socialization perspective. Hum Commun Res 34, 50-69.

37. Which? (2014) Five pricing tactics to watch out for in supermarkets. http://www.which.co.uk/news/2014/02/five-pricingtactics-to-watch-out-for-in-supermarkets-354071/ (accessed February 2014).

38. Smithers R (2014) Tesco bans sweets from checkouts in all stores. The Guardian, 22 May. http://www.theguardian.com/ business/2014/may/22/tesco-bans-sweets-from-checkoutsall-stores (accessed May 2014).

39. Rankin J (2014) Lidl bans sweets at the checkout. The Guardian, 13 January. http://www.theguardian.com/ business/2014/jan/13/lidl-bans-sweets-at-checkout (accessed January 2014).

40. Ofcom (2010) HFSS advertising restrictions - Final review. http://stakeholders.ofcom.org.uk/market-data-research/other/ tv-research/hfss-final-review/ (accessed July 2010). 